\title{
Right To Health Litigation In Brazil: The Problem And The Institutional Responses
}

\author{
Daniel Wei L. Wang \\ Assistant Lecturer, Queen Mary University of London
}

\begin{abstract}
This article first analyses how courts, by applying the right to health as a trump against rationing decisions, have become a relevant healthcare policy-maker in Brazil. Based on empirical findings, it argues that right to health litigation makes the Brazilian public health system less fair and efficient. It then discusses three responses to the negative impact of litigation on the health system: the public hearing held by the Supreme Federal Court and the test established thereafter; the recommendations by the National Council of Justice aimed at building courts' institutional capacity; and Federal Law 12.401/11, which created a new health technology assessment system. Based on a comparative institutional analysis, it concludes that the latter response is the most adequate because it keeps the substantial decisions on the allocation of healthcare resources in the institution that has better capacity to make them and facilitates the judicial control of procedure.
\end{abstract}

KEYWORDS: Right to health; social rights; Brazil; health technology assessment 


\section{INTRODUCTION}

Imagine a healthcare policy with the following features: scientific evidence plays almost no role in it because stringent analysis of treatments' effectiveness or safety is not an essential requirement; treatments' cost-effectiveness will not be assessed either and hence the efficiency in the public spending is ignored; the distribution of beneficiaries is not made according to any reasonable principle of distributive justice, but rather to an individual's capacity to litigate; and no matter if other needs are more urgent, the possibility of alternative use of the resources, or the preference of elected representatives, public authorities or other stakeholders, this policy has to be implemented. From any perspective this would be a bad healthcare policy and would never fulfil the requirements of a fair and efficient public health system. However, this is how Brazilian courts are allocating a significant amount of the public resources when enforcing the right to health as an individual trump against healthcare rationing decisions.

The Brazilian Federal Constitution declares that the right to health is a fundamental right of all and a duty of the State, and established a public health system based on the principles of universality, equality of access and comprehensive coverage (Article 196-8). Brazilian judges were also given the power to consider any case in which a right is threatened or violated (Article 5, XXXV), and a claim against the State can be issued via ordinary actions, class actions (ação civil pública), a protection writ against public authorities (mandado de segurança), and special procedures in small-claim courts (juizados especiais), where legal representation is not necessary. These constitutional and jurisdictional provisions have entitled citizens who were denied a certain health treatment by the public health system to sue the State claiming that they have the right to receive the treatment they need from or funded by the public health system. This phenomenon will be called right to health litigation in this article. 
Right to health litigation in Brazil has already been discussed in the literature on social rights adjudication. ${ }^{1}$ This article, however, presents a more comprehensive review of the empirical findings which provides more solid grounds for answering three questions: what is demanded by claimants; the economic impact of the decisions on the public health budget; and how courts judge these cases. The data reveal that litigation in Brazil has reached an impressive scale and has made of courts a major player in the allocation of healthcare resources, but in a way that makes the public health system less fair and efficient.

The second part of this article compares three responses and the institutions they create to control the negative impact of litigation on the public health system: the public hearing held by the Supreme Federal Court (STF) and the test established thereafter to define a sphere of judicial self-restraint; the recommendations by the National Council of Justice (CNJ) aimed at building courts' institutional capacity; and the enactment of Federal Law 12.401/11, which created a new health technology assessment system.

Claims for the provision of health treatments, although not necessarily using the language of the right to health, are certainly not a phenomenon restricted to Brazil. In many jurisdictions the expansion of judicial power to cover issues of social policies, the increase in the cost of healthcare, and better informed and less acquiescent patients have all brought to courts discussions about priority-setting in healthcare that were in the past left to the entire discretion of legislatures and health authorities. ${ }^{2}$

\footnotetext{
${ }^{1}$ See Octavio Motta Ferraz, 'The right to health in the courts of Brazil: worsening health inequities?'(2009), 11 Health and Human Rights 33; Octavio Motta Ferraz, 'Harming the Poor Through Social Rights Litigation: Lessons from Brazil' (2012) 89 Texas Law Review 1643; Octavio Motta Ferraz, 'Brazil. Health inequalities, rights and courts: the social impact of the judicialization of health', in Alicia Ely Yamin and Siri Gloppen (eds), Litigating Health Rights: Can Courts Bring More Justice to Health? (2011); Mariana Motta Prado, 'The Debatable Role of Courts in Brazil's Health Care System: Does Litigation Harm or Help?' (2013) 41 The Journal of Law, Medicine \& Ethics 124; Florian Hoffman and Fernando Bentes, 'Accountability and Social and Economic Rights in Brazil' in Varun Gauriand Daniel Brinks (eds) Courting Social Justice: Judicial Enforcement of Social and Economic Rights in the Developing World (2010).

2 See Hans V Hogerzeil et al., 'Is access to essential medicines as part of the fulfillment of the right to health enforceable through the courts?' (2006) 368 The Lancet 305; Yamin and Gloppen, supra n 1; Malcolm Langford (ed.)Social Rights Jurisprudence(2008); David Landau, 'The Reality of Social Rights Enforcement' (2012) 53
} 
The analysis of the case of Brazil in this article can offer important lessons for the legal and policy debates on this worldwide phenomenon. First, it presents robust empirical data to show how and why adjudicating health rights, at least via individual complaints, can create an overall undesirable outcome for a public health system by making it less fair and efficient. Second, the comparison between the different institutional responses to right to health litigation challenges the expediency of the idea proposed by part of the literature on social rights adjudication that courts should build their own institutional capacity to adjudicate on social policy issues. Third, it argues that a robust health technology assessment system creates strong reasons for courts, instead of allocating healthcare resources themselves, to control authorities' decision making process, which can make the health system more, rather than less, fair and efficient.

\section{RIGHT TO HEALTH LITIGATION: UNFAIRNESS AND INEFFICIENCY}

This section analyses right to health litigation in Brazil based on empirical evidence regarding what is demanded by claimants, how courts judge the cases, and the economic impact of the decisions on the public budget.

Brazil is organized in a federal system and the analysis will be based on the data about right to health litigation at the federal level and in the states of Santa Catarina, Rio de Janeiro, Minas Gerais, Sao Paulo and Rio Grande do Sul. ${ }^{3}$ This is where most of the right to health

Harvard International Law Journal 402; Ole Norheim and Bruce Wilson, 'Health Rights Litigation and Access to Medicines: Priority Classification of Successful Cases from Costa Rica's Constitutional Chamber of the Supreme Court' (2014) 16 Health and Human Rights Journal 47; Colleen Flood and YY Brandom Chen, 'Charter Rights and Health Care Funding: A Typology of Canadian Health Rights Litigation' (2010) 19 Annals of Health Law 479; Colleen Flood and Ayel Gross, 'Litigating the Right to Health: What Can We Learn from a Comparative Law and Health Care Systems Approach' (2014) 16 Health and Human Rights 62; Katherine Young, Constituting Economic and Social Rights (2012); Sandra Fredman, Human Rights Transformed: Positive Rights and Positive Duties (2008); Keith Syrett, 'Health technology appraisal and the courts: accountability for reasonableness and the judicial model of procedural justice' (2011) 6 Health Economics, Policy and Law 469; Christopher Newdick, Who Should We Treat: rights, rationing, and resources in the NHS (2004).

${ }^{3}$ In Brazil there is a national public health system, the Sistema Único de Saúde (SUS), and the responsibility for provision of health services is shared by every entity of the Federation. Therefore, there are more than 5,500 municipalities, 26 states, the Federal District and the federal government that can be sued by patients willing to 
litigation in the country is concentrated. ${ }^{4}$ Litigation in the capital cities of three of these states, where the population is concentrated, will also be analysed.

\section{A. What Is Demanded}

Right to health litigation is mainly driven by individual claims for new health technologies, especially drugs, which have not been incorporated in the national public health system's (SUS) pharmaceutical policy. The percentage of cases in which claimants demanded drugs not incorporated in the SUS's pharmaceutical policy is high $-80.6 \%$ in the state of Rio de Janeiro, ${ }^{5}$ and $92.5 \%$ in the city of Rio de Janeiro. ${ }^{6}$ Other articles, instead of analysing the percentage of lawsuits in which a non-incorporated drug was demanded, assessed the percentage of non-incorporated drugs among all drugs judicially claimed $-62.2 \%$ in the state of Santa Catarina; ${ }^{7} 68 \%$ in the city of Florianopolis; ${ }^{8} 77 \%$ and $66.2 \%$ in the state of Sao Paulo; ${ }^{9}$ and $38 \%$ in the city of Sao Paulo. ${ }^{10}$

It is important to highlight the difference between these two methods for calculating the data. The second method - which counts the number of non-included drugs among all those judicially claimed - underestimates the importance of claims for non-incorporated drugs as

access treatments not provided by the public health system. The Brazilian courts have constantly decided that a citizen can judicially claim health treatment against any level of government (Daniel Wang et al., 'The impact of health care judicialization in the city of Sao Paulo: public expenditure and federal organization' (2013) 48 Revista de Administração Pública 1191).

4 National Council of Justice. Relatórios de cumprimento da Resolução CNJ n. 107, available at: www.cnj.jus.br/images/programas/forumdasaude/demandasnostribunais.forumSaude.pdf [last accessed 23 July 2015].

${ }^{5}$ Vera Lucia Edais Pepe et al., 'Characterization of lawsuits for the supply of 'essential' medicines in the State of Rio de Janeiro, Brazil’ (2010) 26 Cadernos de Saúde Pública 461.

${ }^{6}$ Tatiana Aragão Figueiredo, Análise dos medicamentos fornecidos por mandado judicial na Comarca do Rio de Janeiro: A aplicação de evidências científicas no processo de tomada de decisão (Masters dissertation,

Sergio Arouca National School of Public Health, 2010).

7 Januaria Ramos Pereira et al., 'Situation of lawsuits concerning the access to medical products by the Health Department of Santa Catarina State, Brazil' (2010) 15 Ciência \& Saúde Coletiva 3551.

${ }^{8}$ Silvana Nair Leite et al., 'Ações judiciais e demandas administrativas na garantia do direito de acesso a medicamentos em Florianópolis-SC' (2009)10 Revista de Direito Sanitário 13.

9 Ana Chieffi and Rita Barata, 'Judicialization of public health policy for distribution of medicines' (2009) 25 Cadernos de Saúde Pública 1839; Eloisa Israel Macedo et al., 'A technical analysis of medicines request-related decision making in Brazilian courts' (2011) 45 Revista de Saúde Pública 706.

${ }^{10}$ Fabiola Vieira and Paola Zucchi, 'Distorções causadas pelas ações judiciais à política de medicamentos no Brasil' (2007) 41 Revista de Saúde Pública 214. 
the main driver of right to health litigation. In many cases, patients demand more than one drug. For example, in the case of the state of Rio de Janeiro it was found that among the drugs judicially claimed, $52 \%$ were not incorporated in the pharmaceutical policy. ${ }^{11}$ However, when analysing the number of cases in which at least one of these drugs is claimed, the number rises to $80.6 \%$.

One plausible hypothesis to explain this difference is that when people litigate for an expensive medicine, they make the most of their effort and include all the medicines that are in the same medical prescription that contains the expensive drug that is really motivating the litigation. In other words, drugs included in the pharmaceutical policy are 'free riders' and are claimed together with drugs not provided by the health system. Litigants would do it because if they have a judicial decision in their favour, they will receive the drugs in more convenient conditions. The Federal Government, for instance, when complying with a judicial decision, delivers the drug by mail to the patient's house. ${ }^{12}$ Moreover, patients make sure that their supply will not be interrupted, as may happen to other patients, since health authorities will not stop providing the drugs because contempt of court is a criminal offence. In the state of Sao Paulo it was found that in $87 \%$ of the cases in which patients were litigating for drugs already provided by the public health system, they were also claiming access to nonincorporated treatments. $^{13}$

\footnotetext{
${ }^{11}$ Pepe et al., supra n 5; See also Joao Sant'Anna. Essencialidade e assistência farmacêutica: um estudo exploratório das demandas judiciais individuais para acesso a medicamentos no Estado do Rio de Janeiro (Masters dissertation, Sergio Arouca National School of Public Health, 2009).

${ }_{12}$ Ministry of Health and The Federal Attorney General's Office, Intervenção Judicial na Saúde Pública: Panorama no âmbito da Justiça Federal e Apontamentos na seara das Justiças Estaduais, available at: www.portalsaude.saude.gov.br/images/pdf/2014/maio/29/Panorama-da-judicializa----0---2012---modificadoem-junho-de-2013.pdf [last accessed 23 July 2015].

${ }^{13}$ Wang et al., 'Incorporating drugs through litigation: the case of the State of Sao Paulo' (Annual Meeting of the Law and Society Association, 2012).
} 
It was also noticed that in many cases patients went to court claiming drugs that belong to the pharmaceutical policy because they were prescribed for off-label or off-protocol use. ${ }^{14}$ The former means the prescription of a drug for unapproved clinical indications or to unapproved subpopulations; the latter is the prescription of drugs that are incorporated in the SUS to patients who do not meet the clinical criteria established by clinical protocols and guidelines. For instance, Eloisa Macedo et al. analysed claims for high cost drugs incorporated in the SUS and found that in $81.3 \%$ of them the clinical guidelines and protocols did not recommend their use for the claimant's condition. ${ }^{15}$

There is also a small percentage of litigation claiming drugs that are not registered with the Brazilian National Health Surveillance Agency (ANVISA), the agency responsible for barring unsafe and unproven drugs for use in the country. ${ }^{16}$ In cases where courts order the provision of drugs not registered with the ANVISA or authorise off-label use, they are ordering the provision of treatments the effectiveness and safety of which have not been evaluated or approved by the agency.

In these cases, besides the risk to patients, the cost of providing these treatments can be very high. For example, in the state of Sao Paulo, R $\$ 40$ million (around US\$19 million) ${ }^{17}$ was spent to comply with judicial decisions ordering drugs for cancer from 2005 to 2006 . However, $17 \%$ of this amount was spent on drugs without scientific evidence that they could bring any benefit to patients who were claiming them, either because the drug was not registered with the ANVISA or because it was not recommended for the claimants' condition

\footnotetext{
${ }^{14}$ Marina Amaral de Avila Machado et al., 'Judicialization of access to medicines in Minas Gerais state, South eastern Brazil' (2011) 45 Revista de Saúde Pública 590; Wang et al., supra n 13; Figueiredo, supra n 6; Ana Maria Messeder et al., 'Mandados judiciais como ferramentas para garantia do acesso a medicamentos no setor público: a experiência do Estado do Rio de Janeiro, Brasil' (2005) 21 Cadernos de Saúde Pública 525.

${ }^{15}$ Macedo et al., supra $\mathrm{n} 9$ at 709.

${ }^{16}$ See Machado et al., supra n 14; Pereira et al., supra n 7; Pepe et al., supra n 5; Figueiredo, supra n 6; Chieffi and Barata, supra n 9; Vieira and Zucchi, supra n 10.

${ }^{17}$ The values in US dollars in this article were calculated using the average exchange rate in the last month of the respective year.
} 
according to the existing clinical guidelines and protocols (off-protocol use). ${ }^{18}$ Similar data was found by Fabiola Vieira and Paola Zucchi: ${ }^{19} 3$ out of 10 kinds of drugs for cancer provided by the city of Sao Paulo in compliance with judicial orders were not registered with the ANVISA and most of the rest lacked evidence of their effectiveness in the claimants' circumstances. It is also important to highlight that drugs for cancer are extremely expensive. In the city of Sao Paulo, just $7.2 \%$ of the drugs supplied to comply with judicial orders were drugs for cancer, although $75 \%$ of the total spent to buy judicially ordered medicines was spent on oncology drugs. ${ }^{20}$

Apart from drugs, courts have also ordered the provision of other treatments without robust evidence of safety and effectiveness. In the case STA 223 (2008), the Supreme Federal Court (STF) decided that the health system should pay for surgery that could only be performed by an American surgeon, who had to be brought to Brazil with all expenses (flights, hotel and a US\$150,000 treatment) paid for by the State. The surgery was not approved by the American FDA and was never evaluated by the ANVISA. In RE 368546 (2011) the STF decided that six people had the right to receive treatment for pigment rethinosis in Cuba, with all expenses covered by the State, in spite of the medical consensus affirming that this treatment does not work. ${ }^{21}$ In a recent decision, the Ministry of Health was ordered to pay for an experimental US\$870,000 surgery in the United States and also for all expenses related to the patient and her parents' transportation and living costs abroad. ${ }^{22}$

The effectiveness and safety of treatments should be the first things to be considered when designing healthcare policies. However, there is another element that cannot be

\footnotetext{
${ }^{18}$ Luciane Lopes et al., 'Rational use of anticancer drugs and patient lawsuits in the state of São Paulo, South eastern Brazil', (2010) 44 Revista de Saúde Pública 620.

${ }^{19}$ Vieira and Zucchi, supra n 10.

${ }^{20}$ Ibid.

${ }^{21}$ The Brazilian Ophthalmology Association, the institution that represents ophthalmologists in the country, participated in the judicial procedure and confirmed before the STF that the treatment is ineffective.

${ }^{22}$ Octavio Ferraz and Daniel Wang, 'As Duas Portas do SUS' (2014), Folha De São Paulo at A3.
} 
neglected: cost-effectiveness. Even if it is proved that a new treatment is safe and effective, it is important to assess whether it is more effective than the existing treatments and, if it is, whether its costs compensate the gains in health it produces. Ideally, patients would be cared for with the best treatments available, but the scarcity of resources is a ubiquitous reality and therefore cost-effectiveness should be taken into consideration by health systems in deciding what can be provided to patients.

Marina Machado et al. found that there were alternative treatments available in the SUS for $73 \%$ of the drugs not included in pharmaceutical policy that were provided via judicial order. $^{23}$. In Fabiola Vieira and Paola Zucchi's sample this rate was $80 \%{ }^{24}$ In these cases patients were demanding modern (and more expensive) treatments that are allegedly better than the drugs available in the SUS.

The case of the analogous insulin, the most litigated treatment in the state of Sao Paulo and the cities of Sao Paulo and Rio de Janeiro ${ }^{25}$ is an interesting example. The SUS provides human insulin to patients, but litigants want to have free access to the so-called analogous insulin, the use of which is more convenient to patients. The Brazilian Ministry of Health has steadily refused to provide the analogous insulin on the basis that there is no robust scientific evidence that it is more effective than human insulin for the control of diabetes. ${ }^{26}$ The cost of analogous insulin is also a relevant reason for the SUS not providing what some patients and doctors prefer. The National Council for Incorporation of Technologies in the SUS (see section 3.B) has recently assessed two types of analogous insulin and did not recommend

\footnotetext{
${ }^{23}$ Machado et al., supra n 14.

${ }^{24}$ Vieira and Zucchi, supra n 10.

${ }^{25}$ See Afonso da Silva and Fernanda Terrazas, 'Claiming the Right to Health in Brazilian Courts: The Exclusion of the Already Excluded' (2011) 36 Law and Social Inquiry 82; Daniel Wei Liang Wang et al., 'Judiciário e fornecimento de insulinas análogas pelo sistema público de saúde: direitos, ciência e políticas publicas' (Projeto Casoteca Direito GV, 2011); Figueiredo, supra n 6; Daniel Wang and Octavio Motta Ferraz, 'Reaching out to the needy? Access to justice and public attorneys' role in right to health litigation in the city of Sao Paulo' (2013) 18 SUR International Journal on Human Rights 159.

${ }^{26}$ Ministry of Health, Relação Nacional de Medicamentos Essenciais. 6a edição. Série B - textos básicos de saúde (Brasilia, 2008). See also A Siebenhofer, et al., 'Short acting insulin analogues versus regular human insulin in patients with diabetes mellitus (Review)' (2009) The Cochrane Library.
} 
their incorporation in the SUS. It did not find strong evidence that they are more effective than the human insulin and it would cost six times more for the SUS to provide the analogous instead of the human insulin, an incremental cost of R $\$ 13.5$ billion (around US $\$ 5.4$ billion) over five years. ${ }^{27}$ For most judges, however, if the patient has a prescription for the analogous insulin, then her right to health will trump priority-setting considerations. ${ }^{28}$

Lastly, Ole Norheim and Siri Gloppen developed a methodology using Quality Adjusted Life Years (QALY) and the country GDP per capita to establish thresholds to grade health treatments according to levels of priority for the population. Applying this methodology to a sample of litigated drugs in Brazil, the authors concluded that most of them should be classified as having a low priority, since they provide small or marginal health benefits at a high opportunity cost for the healthcare system. ${ }^{29}$

\section{B. How Courts Judge}

Camila Duran et al. analysed 144 cases demanding HIV drugs that were not incorporated in SUS's policy for HIV and found that the State of Sao Paulo Court of Appeal judged 85\% of them in favour of the patient. ${ }^{30}$. Moreover, in the lower courts, the rate of success is absolute: all cases were judged in favour of the patient. The court's predominant view is that the right to health is an individual right and only in a small number of cases did it consider that economic and policy reasons can be used to justify the non-provision of a drug to a patient.

Silvia Marques and Sueli Dallari analysed cases judged by lower courts in the state of Sao Paulo and found that patients won in more than $90 \%$ of the cases. ${ }^{31}$ Additionally, in more

\footnotetext{
${ }^{27}$ Ministry of Health, Insulinas Análogas de Longa Duração - Relatório de Recomendação da Comissão Nacional de Incorporação de Tecnologias no SUS - CONITEC - 103 (Brasília, 2014).

${ }^{28}$ Wang et al., supra $\mathrm{n} 25$.

${ }^{29}$ Olef Norheim and Siri Gloppen, 'Litigating for medicines: how can we assess impact on health outcomes', in Yamin and Gloppen supra $\mathrm{n} 1$ at 313.

${ }^{30}$ Camila Duran et al. 'O Judiciário e as políticas públicas de saúde no Brasil: o caso AIDS'. Prêmio Ipea 40 Anos: Monografias Premiadas (2004).

31 Silvia Badim Marques and Sueli Gandolfi Dallari, 'Safeguarding of the social right to pharmaceutical assistance in the state of São Paulo, Brazil' (2007) 41 Revista de Saúde Pública 101.
} 
than $80 \%$ of the decisions, the judge affirmed that the patient's right to comprehensive healthcare should be guaranteed and could not be restricted by budgetary or policy considerations. Grinover et al. found that, from 2010 to 2012, the State of Sao Paulo Court of Appeal, the State of Minas Gerais Court of Appeal and the $3^{\text {rd }}$ Circuit Federal Court of Appeal have judged over $90 \%$ of the cases in favour of the litigant patient. ${ }^{32}$.

Vera Pepe et al. ${ }^{33}$ and Joao Santa'Anna ${ }^{34}$ found that patients won $100 \%$ of the cases in the lower courts in the state of Rio de Janeiro. Joao Santa'Anna also found that patients won all the cases in the Court of Appeal. ${ }^{35}$ In the sample analysed by Miriam Ventura et al. all the claimants in the city of Rio de Janeiro had injunctions decided in their favour. ${ }^{36}$ In the state of Rio Grande do Sul, in $93 \%$ of the cases the claimant had an injunction granted by the court, in $96 \%$ of them the final ruling in the lower courts was completely or partially in favour of patients, and $89 \%$ of the cases that reached the State of Rio Grande do Sul Court of Appeal were decided in favour of patients. ${ }^{37}$

Daniel Wang et al. analysed how 12 courts (the Supreme Federal Court, the Superior Court of Justice, five State Courts of Appeal and five Federal Courts of Appeal) judged cases in which analogous insulin was claimed. ${ }^{38} 502$ cases were analysed and it was found that patients won in $88 \%$ of them. Furthermore, in five courts the rate of success was $100 \%$ and in two of them, it was more than $95 \%$. The case of the analogous insulin is especially interesting because, as already discussed, there is scientific uncertainty about the benefits of its use as a substitute for regular insulin. This was an argument used by health authorities in courts to

\footnotetext{
${ }^{32}$ Ada Grinover et al., Avaliação da prestação jurisdicional coletiva e individual a partir da judicialização da saúde, CEBEPEJ/DIREITOGV, 2014, available at: Www.cpja.fgv.br/sites/cpja.fgv.br/files/relatorio_final_judializacao_da_saude.pdf [last accessed 23 July 2015].

${ }^{33}$ Pepe et al., supra $\mathrm{n} 5$.

${ }^{34}$ Sant'Anna, supra n 11.

${ }^{35}$ Ibid.

${ }^{36}$ Miriam Ventura et al., 'Judicialização da saúde, acesso à justiça e a efetividade do direito à saúde' (2010), 20 Revista de Saúde Coletiva 77.

${ }^{37}$ João Biehl et al., 'Judicialisation of the right to health in Brazil' (2010), 373 The Lancet 2182.

${ }^{38}$ Wang et al., supra n 25.
} 
justify the non-provision of the analogous insulin, yet in $84 \%$ of the cases courts considered that it was for the patient's doctor, rather than the health authorities, to decide which treatment should be given to them. Hence, according to courts, as long as patients have a prescription affirming that the analogous insulin is necessary, the public health system should provide it without further enquiry as to the quality of the evidence on which the physician's opinion is based.

Similar findings regarding the kind of evidence used by courts was found by Miriam Ventura et al: ${ }^{39}$ in $97 \%$ of the cases the judicial decision decision was based solely on the medical information provided by the claimants' doctors and no further evidence regarding the quality of the treatment, the need of the patient and the alternative treatments was required.

The problem with this deferential attitude towards a doctor's opinion is that physicians do not always base their prescription on the best scientific evidence. ${ }^{40}$ This may happen, for instance, because of the difficulty for practitioners to keep up-to-date with all the new scientific information; the biases in the dissemination of scientific research; the marketing strategies of pharmaceutical companies; and conflict of interests. ${ }^{41}$ Should this judicial reasoning be maintained, courts will become an obstacle for evidence-based medicine in Brazil.

In sum, applicants' high rate of success can be explained by the prevalent interpretation of the right to health as an individual trump against priority-setting decisions, coupled with the lack of stringent scientific evidence requirements for the provision of treatment via courts. This predominant approach to right to health litigation in Brazilian courts is along the lines of the case-law of the STF, the highest court of appeal and the constitutional court.

\footnotetext{
${ }^{39}$ Ventura et al., supra n 36 .

${ }^{40}$ James C Moon et al., 'Getting Better Value from the NHS drug budget' (2010) 341 British Medical Journal 6449 .

${ }^{41}$ See, for instance, Ben Goldacre, Bad Pharma: how drug companies mislead doctors and harm patients (2012).
} 
In the first case decided by the Supreme Federal Court (STF), ${ }^{42}$ the claimant demanded the SUS pay for an experimental treatment only available in the United States (the costs included transportation, treatment and foreign living expenses). In this decision, the STF made a statement that has been constantly quoted in subsequent decisions by other courts and by the STF itself:

[In choosing] between protecting the inviolability of the right to life, an inalienable Constitutional fundamental right, and a financial and secondary interest of the State, I believe - once this dilemma is established - ethical and legal reasons leave the judge with only one possible option: unwavering respect for life.

There were some cases in which the STF departed from the view that the right to health is absolute and recognized that the public health system cannot focus exclusively on the specific needs of the applicant patient and should consider the allocative impact of its decisions. ${ }^{43}$ However, after almost 20 years going back and forth trying to establish criteria for the judicial review of rationing decisions, and in spite of the public hearing held by the court (see section 3.A.i), the interpretation that the right to health entitles patients to receive any health treatment they need, because people's health and life trump 'financial and secondary interests of the State', is still an approach that is prevalent within Brazil's highest court.

The STF is still reluctant to accept that the scarcity of resources and the lack of scientific evidence are acceptable reasons to deny healthcare. It is also worth mentioning again and quoting the case $\mathrm{RE} 368546,{ }^{44}$ in which the government was obliged to provide treatment for Pigment Rethinosis in Cuba despite scientific evidence that it is ineffective. One of the Justices (Marco Aurelio) undermined the extensive evidence against the effectiveness

\footnotetext{
${ }^{42}$ Pet 1246, STF (1997)

43 See Daniel Wang, 'Courts and Health Care Rationing: the case of the Brazilian Federal Supreme Court' (2012) 8 Health Economics, Policy and Law 75.

${ }^{44}$ RE 368546, STF (2011).
} 
of the treatment and the objections against its high costs for the public health budget by affirming that:

I cannot accept that the lack of economic resources can be articulated to deny health care to a citizen ... according to what I read in the media, the successful treatment for this disease is indeed in Cuba.

Similarly, another Justice (Luiz Fux) reasoned that

I am very determined when it comes to hope. I never believed in the version that the pigment rethinosis could not be cured in Cuba. Quite the opposite, I think that they [Cubans] are specialists in this area and there should be hope concerning the cure.

In the most recent case, ${ }^{45}$ the STF decided that the public health system should provide a high cost treatment (US\$409,500 per year) despite the fact that the treatment has never been incorporated in the SUS nor has it been registered with the ANVISA.

\section{(i) Collective claims}

Even though right to health litigation in Brazil is mainly driven by individual lawsuits, ${ }^{46}$ there are also cases of collective claims, normally demanding access to drugs not regularly provided by the SUS to a group of identified patients or to all patients in a given jurisdiction (which can be a city, a state, the Federal District or the Federal Government). ${ }^{47}$ The former are very similar to individual lawsuits and the only difference is that there is more than one claimant. Courts decide these cases in the same way that they decide individual claims. The latter lawsuits, on the other hand, raise different issues because they are more structural in the

\footnotetext{
${ }^{45}$ STA 761, STF (2014).

${ }^{46}$ According to the research carried out by Grinover et al., supra $\mathrm{n} 32$, collective claims represent less than $1 \%$ of the right to health litigation cases in Brazil.

${ }^{47}$ There are also lawsuits requiring the improvement of health facilities (see Wang and Ferraz, supra $\mathrm{n} 25$ ).
} 
sense that they are not a dispute between two parties and may cause far-reaching reform that aims at affecting a multiplicity of parties. ${ }^{48}$

Interestingly, the same courts that show almost no restraint in reviewing rationing decisions in individual cases are more reluctant to decide in favour of claimants when the claim is collective and structural. ${ }^{49}$ As already shown, in individual cases courts tend to ignore the impact of their decisions on the public health budget and on the other users of the SUS; the need to set priorities in health expenditure; and the capacity and legitimacy of courts to assess scientific evidence and to make allocative decisions. Conversely, in collective claims with potentially structural effects all these elements are considered by courts to justify their deference to a rationing decision made by health authorities. ${ }^{50}$

As shown by Daniel Wang et al., ${ }^{51}$ some of the same courts that grant access to analogous insulin to practically any patient who goes individually to claim it, turn down claims for the incorporation of this insulin for regular provision by the SUS. Courts tend to argue that resources are scarce and judges are not in the best position to second-guess the decisions made by health authorities.

Two decisions by the STF make clear the preference for adjudicating the right to health individually rather than collectively: SL 256 (2010) and STA 424 (2010). The latter involved a request for universal provision of three drugs (not incorporated in the SUS) for treating microcephalia. The former was a complaint to oblige the health system to pay for the transport, food and accommodation costs of any patient in the city of Araguaína who needed to receive treatment in another city. The STF rejected both claims, arguing that the judiciary should not require health authorities to fulfill duties that are overly 'general', because this

\footnotetext{
${ }^{48}$ Owen Fiss, 'The Social and Political Foundations of Adjudication' (1982) 6 Law and Human Behavior 121 at 123.

${ }^{49}$ See Wang et al., supra n 25; Wang and Ferraz, supra n 25; Hoffman and Bentes, supra $n 1$ at 224-5.

${ }^{50}$ Wang et al., ibid.; Hoffman and Bentes, ibid.at 224-5.

${ }^{51}$ Wang et al., ibid.
} 
may unduly affect the public budget and would 'impair the regular functioning of the health system administration, reduce efficiency in patient care and limit the available resources'.

Nonetheless, both decisions emphasized that the drugs in the one case, and the transport, food and accommodation in the other, must be provided if the need is proved individually. In the case $S L 256$ (2010), apart from the general demand for the SUS to pay for the transport, food and accommodation to all citizens of Araguaína, there was also a request for the provision of these services to some particular individuals, which was granted by the court.

The fact that individual and collective cases tend to be decided differently can be explained by the fact that in individual lawsuits there is the impression that an individual decision has no potential to cause much impact, whereas a collective claim can have largescale policy implications. ${ }^{52}$ This impression is false because the aggregate effect of individual lawsuits can be enormous, as will be shown in the next section.

\section{The Budgetary Impact}

Right to health litigation has been growing steadily in Brazil in recent years, as well as the economic impact of the decisions on the public health budget. At the federal level, the Ministry of Health expenditure to comply with judicial decisions ordering the supply of health treatments increased from $\mathrm{R} \$ 2.5$ million in 2005 to $\mathrm{R} \$ 244$ million (around US\$135 million) in 2011: a solid 9,660\% increase in six years. The aggregate expenditure by the Federal Government from 2003-11 was around R\$ 588 million (around US\$326 million), $85 \%$ of which was spent in $2009-11 .^{53}$ The impact of a few very expensive drugs is also noteworthy: in 2011, the amount spent on the 20 most expensive drugs that were claimed by

\footnotetext{
${ }^{52}$ See Landau, supra $\mathrm{n} 2$.

${ }^{53}$ The figures were calculated by using the data provided by The Ministry of Health and The Federal Attorney General's Office, supra n 12.
} 
632 patients $(0.05 \%$ of the total litigants in that year), represented $78 \%$ of the total spent by the Ministry of Health to purchase drugs in compliance with judicial orders.

At sub-federal level - states and municipalities - the sheer scale of the impact of right to health litigation is also impressive. In the state of Minas Gerais the amount spent on complying with health litigation decisions increased from $\mathrm{R} \$ 8.5$ million in 2002 to $\mathrm{R} \$ 42.5$ million in 2008 and R\$205 million (US\$85 million) in 2013. This represented 3\% of the state's healthcare budget for that year. ${ }^{54}$ In the state of Rio Grande do Sul the number of lawsuits increased from 1,126 in 2002 to 17,025 in 2009 (an increase of $1,412 \%$ ). ${ }^{55}$ The amount spent by the state of Rio Grande do Sul on health treatments ordered by courts in 2008 represented $22 \%$ of the total amount spent by the state on pharmaceutical drugs and $4 \%$ of the state's projected health budget for that year. ${ }^{56}$

The state of Sao Paulo spent $\mathrm{R} \$ 400$ million in 2008, $\mathrm{R} \$ 512.5$ million in 2009 , and around R\$700 million (US\$411 million) in 2010, an amount equivalent to $5 \%$ of the state budget for healthcare that year. ${ }^{57}$ The number of drugs the supply of which was ordered by judicial decision increased from 799 in 2005 to 14,563 in 2010 and to almost 19,000 in 2013. ${ }^{58}$ Michel Naffah Filho et al. estimated that in 2010 the state of Sao Paulo spent 4.5 times more in complying with judicial decisions than on hospitalization for organ transplantation. The total amount was also equivalent to $90 \%$ of what was spent on the 123 million clinical diagnoses made by the public health system in the whole state of Sao Paulo;

\footnotetext{
${ }^{54}$ Machado et al., supra n 14; data provided by the state of Minas Secretary of Health to the author on the $31^{\text {st }}$ August, 2014; and public budget information available in the website of the Legislative Assembly of the State of Minas Gerais, available atwww.politicaspublicas.almg.gov.br [last accessed 23 July 2015].

${ }^{55}$ Biehl et al., supra n 37.

56 Ibid.

${ }^{57}$ Michel Naffah Filho et al., 'S-Codes: a new system of information on lawsuits of the State Department of Health of São Paulo (2010) 7 Boletim Epidemiológico Paulista 18; Ministry of Health and The Federal Attorney General's Office, supra n 12; Cristiane Segatto, 'O paciente de R $\$ 800$ mil' (2012), Epoca, available at: www.revistaepoca.globo.com/tempo/noticia/2012/03/o-paciente-de-r-800-mil.html [last accessed 23 July 2015]; budget information available at the Finance Secretary of the state of São Paulo, available at www.fazenda.sp.gov.br [last accessed 23 July 2015].

${ }^{58}$ Naffah Filho et al., ibid.; data provided to the author by the state of São Paulo Attorney's Office.
} 
$28 \%$ more than what was spent on dialysis; and $29 \%$ more than what was spent on chemotherapy and radiotherapy. ${ }^{59}$

In the state of Santa Catarina, the amount spent increased from $\mathrm{R} \$ 38,362$ in 2001 to over R\$6.5 million in $2004^{60}$ and $\mathrm{R} \$ 93$ million (US\$54 million) in $2010{ }^{61}$ Another interesting finding in the state of Santa Catarina is that the drugs claimed through courts are getting more and more expensive. In 2001, the average cost per drug was $\mathrm{R} \$ 2,019$ and increased to $\mathrm{R} \$ 8,157$ (US\$3,000) in 2004 . That means that not only are more drugs being litigated for, but also that more expensive drugs are being claimed through litigation. ${ }^{62}$

At municipal level, the increase in litigation and its costs is also relevant. In the city of Florianopolis, there was a $3,944 \%$ increase in expenditure on drugs ordered by judicial decision: from $\mathrm{R} \$ 3,398$ in 2003 to $\mathrm{R} \$ 137,429$ (US\$65,400) in $2006 .^{63}$ In the city of Sao Paulo it was estimated that the amount spent on complying with right to health litigation decisions in 2011 was around R $\$ 8.9$ million (US\$5 million). This amount represented $10 \%$ of the city's budget for the pharmaceutical policy in that year. ${ }^{64}$ In cities with smaller budgets, the impact of right to health litigation can be even more dramatic. For example, in Buritana, a small city of 15,000 inhabitants, more than $50 \%$ of the budget for drugs was spent on providing treatment ordered by courts and one single patient won in court the right to receive a treatment that will cost the municipality $16 \%$ of its entire budget for drugs. ${ }^{65}$

In 2009, a survey sent by email and posted to all the 5,564 Brazilian cities tried to measure the impact of health litigation at municipal level. $24 \%(1,276)$ of the cities answered

\footnotetext{
${ }^{59}$ Ibid. at 28.

${ }^{60}$ Pereira et al., supra $n 7$.

${ }^{61}$ National Council of Justice, SP, RS e RJ são estados que mais concentram processos na área de Saúde, available at: www.cnj.jus.br/noticias/cnj/57537-sp-rs-e-rj-sao-estados-que-mais-concentram-processos-na-areade-saude [last accessed 23 July 2015].

${ }_{62}$ Pereira et al., supra $n 7$.

${ }^{63}$ Leite et al., supra $\mathrm{n} 8$.

${ }^{64}$ Wang et al., supra $\mathrm{n} 3$.

${ }^{65}$ Segatto, supra n 57.
} 
the survey. The result was that more than $50 \%$ of the cities affirmed that they were facing an increase in right to health litigation cases. One third of the respondents affirmed that health litigation was an 'important problem' for them. Respondents were also asked to provide information concerning the number of lawsuits they had to respond to and the amount of money that was spent on complying with those cases decided in favour of patients. The result was that the number of lawsuits and the amount spent on complying with decisions in the first semester of 2009 had outpaced the total amount in 2007 and was close to the total in $2008 .^{66}$

In conclusion, the resources spent by the public health system on complying with judicial decisions are already very significant and are consuming an increasingly large amount of the public health budget. Given that the public health budget's growth cannot keep up with the growth in litigation, courts are having a major impact in reallocating public healthcare resources in Brazil by compelling the provision of treatments without proper appraisal of their safety or effectiveness. Courts show almost complete disregard for policy considerations such as cost-effectiveness, fairness, budgetary capacity of the state and the health needs of the population. Moreover, given that litigation is mainly driven by individual claims, courts are forcing an increase in expenditure on goods that can be individually consumed (e.g. drugs) rather than on common goods and public services that benefit whole populations (e.g. preventative health programmes).

Litigation also creates a two-tier public health system - one upper-tier for those who can litigate and have access to any treatment irrespective of cost, and the other for the rest of the population who have access to more limited care. Healthcare resources are distributed according to a morally arbitrary principle, the capacity to litigate, which is certainly not

\footnotetext{
${ }^{66}$ Ferraz, 'Brazil', supra n 1.
} 
evenly distributed in society. ${ }^{67}$ It can be expected, however, that right to health litigation will progressively become more accessible as people are better informed, there is more public investment in legal aid, and pharmaceutical companies have incentives to encourage litigation. ${ }^{68}$ This can make right to health litigation apparently less unfair, but the fact that more people litigate and thus go up to the upper-tier created by courts means that litigation will affect more severely the rest of the population in the tier below.

\section{THE INSTITUTIONAL RESPONSES}

The impact of courts on healthcare policies has become too big to be ignored and this section will discuss the three most overarching responses to control its negative impact on the public health system.

Two come from the highest institutions of the judicial branch and the third is the Federal Law 12.401/11. All these proposals have in common the fact that they try to establish a sphere of judicial restraint in which courts should defer to the decisions made by health authorities. Thus, they try to oppose the Brazilian courts' prevailing interpretation that there is an individual right to receive healthcare that cannot be restricted by health authorities' priority setting decisions or the lack of robust scientific evidence.

However, they disagree on what courts should do when there are claims for drugs not incorporated in the SUS pharmaceutical policy. And this is a central issue since, as discussed in section 2, these claims are the main drivers of right to health litigation in Brazil.

\footnotetext{
${ }^{67}$ There is data indicating that right to health litigation creates an anti-poor bias because claimants from higher socio-economic groups tend to be over-represented in these cases. See Afonso da Silva and Terrazas, supra n 25; Ferraz, 'Harming', supra n1; Wang and Ferraz, supra n 25. See, however, Joao Biehl et al., 'Between the court and the clinic: lawsuit for medicines and the right to health in Brazil' (2012), 14 Health and Human Rights 36; Marcelo Medeiros et al., 'The thesis of judicialization of health care by the elites: medication for mucopolysaccharidosis' (2013) 18 Ciência \& Saúde Coletiva 1089.

${ }^{68}$ The evidence on pharmaceutical companies encouraging and funding right to health litigation by connecting patients, doctors and lawyers is abundant. See Anna Chieffi and Rita Barata, 'Ações judiciais: estratégia da indústria farmacêutica para introdução de novos medicamentos' (2010), 44 Rev Saúde Pública 421; Naffah Filho et al, supra n 57; Medeiros et al., supra n 67; Daniel Wang and Octavio Ferraz. 'Pharmaceutical Companies vs. the State: Who Is Responsible for Post-Trial Provision of Drugs in Brazil?' (2012) 40 The Journal of Law, Medicine \& Ethics 188.
} 


\section{A. Self-Restraint and Institutional Capacity: Responses from the Judicial Branch}

Concerns about courts' lack of institutional capacity and the limits of the adjudicative process are some of the most common critiques against courts deciding on the provision of welfare benefits via social rights adjudication. Judges, according to this argument, are trained in law and legal process and have neither the knowledge, expertise, qualifications or experience to decide on multifaceted issues of policies, especially those involving the allocation of scarce resources. Moreover, the adversarial model of adjudication tends to reduce polycentric problems which 'involve many affected parties and a somewhat fluid state of affairs' to bilateral disputes and is poorly prepared to gather and analyse complex social data. ${ }^{69}$ Courts will know a lot about a case, but little about its milieu and thus will not be able to see the trade-offs in the competition for budgetary resources or political follow-throughs. ${ }^{70}$

On the other hand, those who advocate for a more active role of courts in social rights adjudication affirm that courts, when protecting civil and political rights, also deal with complex issues that may be very similar to those raised by social rights adjudication. Thus, the judicial protection of social rights creates challenges for courts that are not so different from those they commonly face. Furthermore, judges can be provided with relevant information by the parties, their lawyers, witnesses and court appointed individual experts and bodies. Some individual judges can also specialize in social rights adjudication through experience and legal education, in the same way that they specialize in other fields of law. Finally, the judicial process can be made more participatory - open to amici curiae and public hearing - to enable courts to deal with the complex issues brought before them in cases involving social rights. ${ }^{71}$

\footnotetext{
${ }^{69}$ Lon Fuller, 'The Forms and Limits of Adjudication' (1978), 92 Harvard Law Review 353 at 394.

${ }^{70}$ Donald Horowitz, 'Umpire or Empire?' (1982), 6 Law and Human Behaviour 129.

${ }^{71}$ See, for instance, Aoife Nolan, et al., 'The Justiciability of Social And Economic Rights: An Updated Appraisal' (Center for Human Rights and Global Justice Working Paper, 2007), at 14-15; Virgina Mantouvalou, 'In Support of Legislation' in Conor Gearty and Virginia Mantouvalou, Debating Social Rights (2011); Roberto
} 
The response to right to health litigation advanced by the Supreme Federal Court (STF) and the National Council of Justice (CNJ) can be contextualized in this debate about the capacity of courts and of the adjudicative process to decide properly on the provision of welfare policies. Both institutions recognize that courts have institutional limitations and therefore can only be secondary decision-makers on the issue of healthcare provision. However, at the same time, they try to overcome these limitations in order to give to courts a prominent role in the judicial review of rationing decisions on a case-by-case basis.

The response advanced by the STF and the CNJ can be better understood as complementary parts of the same policy engaged with right to health litigation. This is not surprising since there is a strong connection between both institutions. The CNJ is a formally autonomous institution, but it is expected that the STF, especially its president, will have a significant influence on the CNJ. The presidency of the CNJ, which has a great deal of responsibility in setting the institution's agenda, is chaired by the Chief Justice of the STF. Moreover the STF has the prerogative to appoint other two members of the CNJ. The affinity between the recommendations of the CNJ and the decisions of the STF will be made clearer in the following sub-sections.

\section{(i) The Supreme Federal Court: public hearing and the establishment of a test}

The STF is the last court of appeal in the Brazilian judiciary and the constitutional court. It held a public hearing in 2009 with over fifty experts (including healthcare professionals, public authorities, legal scholars and civil society representatives), heard over a period of six days, to supply the STF with 'technical, scientific, administrative, political and economic' information related to the right to health litigation phenomenon. ${ }^{72}$

Gargarella, 'Dialogic justice in the enforcement of social rights: some initial arguments' in Yamin and Gloppen, supra $\mathrm{n} 1$.

${ }_{72}$ Gilmar Mendes, 'Opening of the public hearing n. 4 at the Supreme Federal Court', Supreme Federal Court, 2009 , available 
The public hearing was motivated by the acknowledgment that litigation has a significant impact on the public health system and that the court needed support from different specialists and stakeholders in order to make better decisions. ${ }^{73}$ Chief-Justice Gilmar Mendes (as he then was) held the public hearing and declared in his opening speech that 'either the idea that courts should have no role in healthcare issues or that there is a right to any health treatment is untenable' and that a balanced view should be found, taking into consideration 'all the judicial decisions' implications without compromising ... the right to health' ${ }^{74}$ Lastly, he affirmed that he expected the 'public hearing would result not only in technical information conducive to assisting in the court's analysis of the cases, but also in support for a broader and pluralist debate for the improvement of health policies' ${ }^{75}$

Initiatives like the public hearings can be seen as a device to defend more activist courts against critics concerning their institutional capacity, but also as a tool for helping them implement their potential for enhancing democracy and participation. Accordingly, there is an expectation that courts can be a forum to ensure that norms are created and applied through a 'collective and inclusive discussion'. ${ }^{76}$ This public hearing held by the STF was praised by analysts as a good example of what courts should do in regard to the protection of the right to health. ${ }^{77}$

It is not the scope of this article to discuss exhaustively whether courts can create collective and inclusive discussion via public hearings. Nonetheless, it is important to mention that the potential benefits of deliberation promoted via public hearings have to be weighed against the possibility that judges 'may cherry-pick from available studies to support

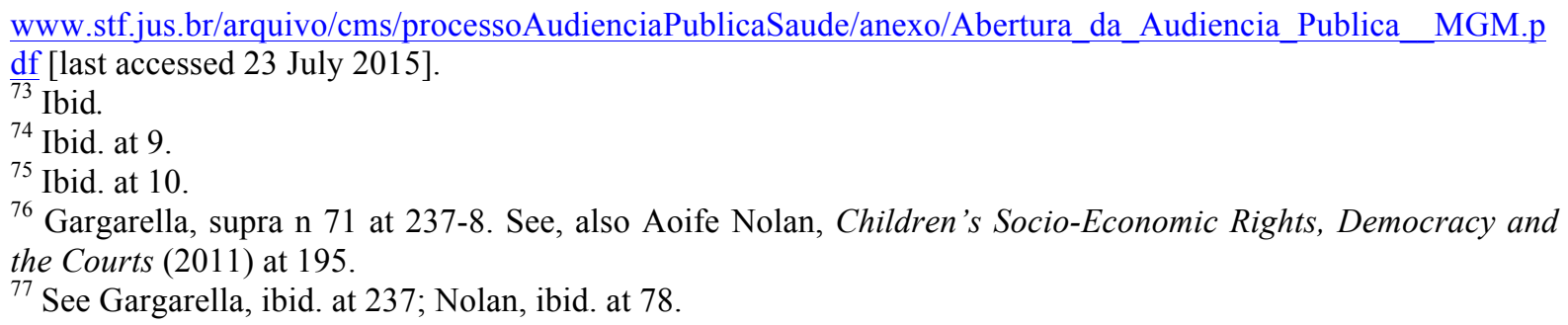


a foregone conclusion', especially when there is a large amount of conflicting data and interpretation of complex facts is required ${ }^{78}$ and that the outcome of the dispute (the judicial decision) may not reflect the deliberation about it given that judges cannot be punished for not grounding their reasons on the deliberation. ${ }^{79}$

A concrete outcome of the public hearing discussed here was the establishment of a test to define those duties citizens can immediately demand from the SUS. This test was established in several cases judged by the STF after the public hearing was held and, according to the STF, it was based on the conclusions drawn from the information presented by the speakers at this public hearing. ${ }^{80}$

It should first be noted that there was an important factual mistake made by the STF when establishing this test. The STF affirmed that most of the litigation is driven by claims for drugs already included in the pharmaceutical policy, a statement that is falsified by the existing evidence (see section 2.A). Moreover, in these decisions there was explicit reference to only a few of the contributions made to the public hearing and the test established by the court draws heavily on the academic work of one participant. ${ }^{81}$ Lastly, in the most recent decisions the STF has simply ignored the discussions that took place during the public hearing and the test established thereafter. It again decided as if the right to health were an individual 'trump', neglecting policy considerations and the need for robust scientific evidence (see section 2.B). These observations about this public hearing vindicate concerns about the court 'cherry-picking' from available data, not grounding its decisions on the

\footnotetext{
${ }^{78}$ Jeff King, Judging Social Rights (2012) at 242.

79 Mark Tushnet, Weak Courts, Strong Rights: Judicial Review and Social Welfare Rights in Comparative Constitutional Law (2008) at 94.

${ }^{80}$ See Wang, supra $\mathrm{n} 43$ at 81.

${ }^{81}$ A very similar test was suggested by Ingo Wolfgang Sarletand Mariana Filchtiner Figueredo. 'Reserva do possível, mínimo existencial e direito à saúde: algumas aproximações' in Ingo Wolfgang Sarlet and Luciano Benetti Timm (eds) Direitos Fundamentais: Orçamento e Reserva do Possível (2008).
} 
deliberation and, therefore, using a participative procedure only to legitimize a foregone conclusion.

With regard to its substantial aspect, the test established by the STF sets some criteria to distinguish those cases when the court should defer to the allocative decisions made by health authorities and those when it should oblige the SUS to offer a treatment allegedly needed by the patient but denied by the government (see Chart below).

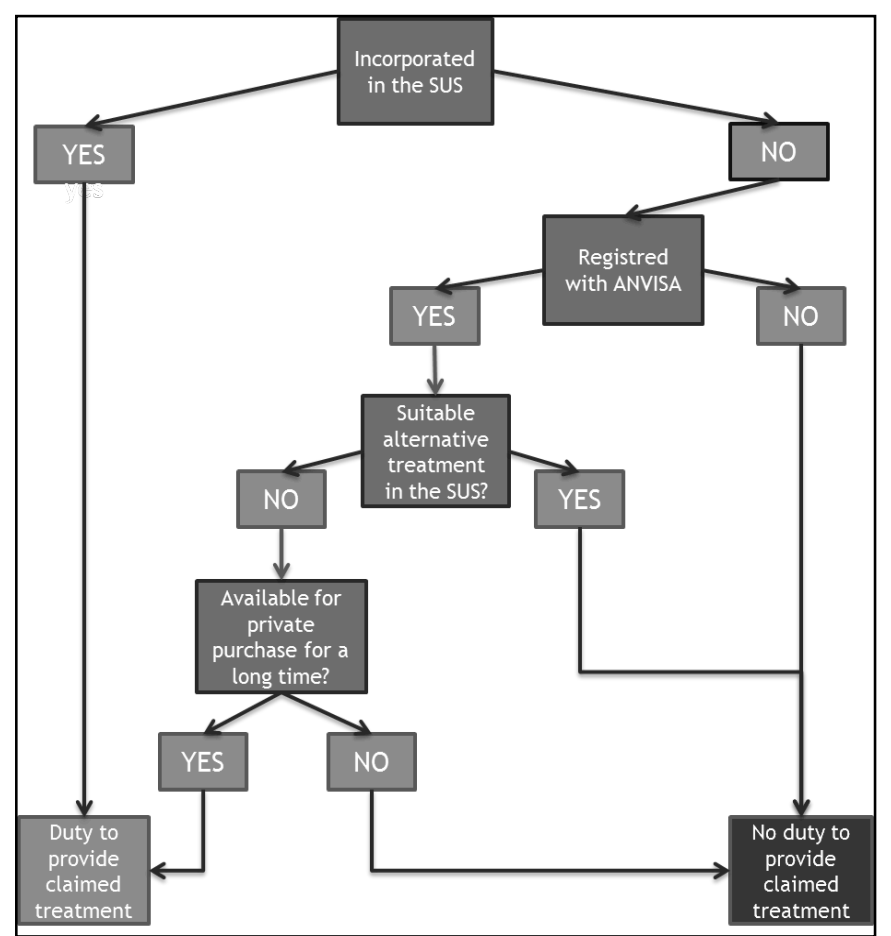

Chart 1 - The STF's test to determine a claimant's right to receive a health treatment

The first criterion establishes that the government cannot deny citizens treatments already incorporated in the SUS, namely, those on the official lists or recommended by clinical protocols and guidelines. If the claimed treatment has not been incorporated, then there is a duty to provide it only if it has been registered with the National Health 
Surveillance Agency (ANVISA); there is no adequate alternative treatment provided by the SUS; and the claimed treatment has been available in the market for a long time. ${ }^{82}$

The test established by the STF aimed at creating a sphere of judicial self-restraint, but also one in which courts could legitimately intervene. Even though this test would rule out the provision of treatments without evidence of effectiveness and safety, or those that are not superior to the existing alternatives, it still ignores policy considerations and allows the adjudication of the right to health as an individual trump.

The STF has not clarified how to determine whether the alternative treatment offered by the SUS is adequate, especially when claimants (together with their lawyers and doctors) and health authorities disagree. This brings us back to the problem of courts' institutional capacity and may help to explain the purpose of the recommendations of the National Council of Justice (CNJ) to build courts' institutional capacity, as will be discussed in the next sub-section.

Moreover, it is not clear either if the alternative offered by the SUS has to be only effective for the patient's health problem or at least as effective as the claimed treatment. A new treatment may be marginally better, but at a much higher cost. The decision about whether a new treatment that is more effective, but more expensive, should be provided in the place of another that is less effective, but cheaper, is one of the biggest challenges for health systems around the world all trying to maximize health benefits with limited resources. ${ }^{83}$

Lastly, the criterion that allows courts to order the supply of a treatment if it has been available in the market for a long time seems to ignore the cost-effectiveness analysis and policy considerations in deciding the provision of healthcare. ${ }^{84}$ The fact that a drug is

\footnotetext{
${ }^{82}$ A longer discussion of this test was made elsewhere, see Wang, supra $\mathrm{n} 43$.

${ }^{83}$ See Harald Schmidt and Julia Kreis, 'Lessons from abroad' (2009), 39 Hastings Center Report 20; Corinna Sorenson and Kalipso Chalkidou, 'Reflections on the evolution of health technology assessment in Europe' (2012), 7 Health Economics, Policy and Law 25.

${ }^{84}$ See Wang, supra n 43.
} 
available for private purchase means only that it is efficient and safe (i.e. registered with the ANVISA), but tells nothing about its cost-effectiveness, level of priority and affordability for the SUS.

In sum, the public hearing has not prevented the STF from underestimating the complexity of healthcare policies and overestimating the capacity of courts to make allocative decisions in healthcare. The same can be said about the response of the $\mathrm{CNJ}$, as will be seen in the following section.

(ii) The National Council of Justice: building courts' institutional capacity

The CNJ is part of the Brazilian judicial branch, but has no judicial power and cannot review judicial decisions. It is an agency responsible for regulating the administrative and financial activities of the judiciary and for the enforcement of judges' professional duties. It can issue resolutions and recommendations for courts in order to improve their functioning in terms of strategic planning and administration.

The CNJ, following on the public hearing held by the STF, issued Recommendation $31 / 2010$ proposing some policies regarding right to health litigation which reinforces and complements what was already put forward by the STF. For the reasons already presented, the affinity between the $\mathrm{CNJ}$ and the STF was to be expected. Justice Gilmar Mendes, the President of the CNJ at the time when Recommendation 31/2010 was issued, was also the Chief-Justice of the STF who organized the public hearing and who wrote the leading opinion of the judgment in which the test discussed in the subsection above was established.

Recommendation $31 / 2010$ 'recommends to courts the implementation of measures aiming at supporting judges and other legal professionals in order to assure better solution for the judicial claims related to healthcare'. It affirmed that the main problems caused by right to health litigation in Brazil were due to the lack of clinical information available to judges in the claims for drugs not approved by the ANVISA. It also stated that the health authority's 
managerial capacity, the existing public policies, the organization of the SUS, and the need to guarantee the sustainability and manageability of the SUS all have to be taken into consideration by courts.

Therefore, the CNJ recommended to Brazilian courts to:

a) Make technical support from doctors and pharmacists available to assist judges in assessing the clinical evidence presented by the litigants in healthcare related cases;

b) Advise judges to analyse the cases based on complete and comprehensive information; to avoid the provision of drugs not registered with the ANVISA or experimental drugs; and to consult, whenever it is possible, health authorities before an interim decision be made;

c) Include health law legislation as a subject to be examined in the public entrance exams for judges and

d) Take judges to visit public health units.

It also recommended the schools responsible for preparing those admitted to the public entrance exams to become judges ${ }^{85}$ to

a) include health law in their curricula and

b) organize seminars with judges, public prosecutors and health authorities in order to promote common views on this topic.

The CNJ, apart from establishing a sphere of self-restraint, innovated in trying to build courts' institutional capacity to decide on the provision of health treatments. ${ }^{86}$ Better trained, informed and assisted judges can impact on right to health litigation in two ways.

First, judges with more information will be able to filter out claims based on poor evidence. Moreover, the more courts know about healthcare policies, the more wary they should be in reviewing the health authorities' rationing decisions because they will be given a broader perspective on the problem than one that is confined to their decision on a claim for

\footnotetext{
${ }^{85}$ In Brazil, lower level courts' judges are chosen via public entrance exams.

${ }^{86}$ Some courts are already implementing some of the recommendations made by the CNJ by creating 'technical support services' composed of doctors, nurses, pharmacists and nutritionists to advise judges in health care litigation cases. See, for instance, Sidharta Ferreira and Aline da Costa, 'Technical advice centers and “judicialization of health”: constitutional or unconstitutional?’ (2013) 20 Revista da SJRJ 219.
} 
the fulfilment of an individual need. They will understand, for instance, that the SUS has to make 'tragic choices', that there are opportunity costs, and that rationing is necessary. ${ }^{87}$.

Second, by building courts' institutional capacity the CNJ tries to create better conditions for judges to second-guess health authorities' decisions concerning the provision of health treatments. It is important to note that Recommendation $31 / 2010$ follows on the public hearing held by the STF and the test established thereafter. According to this test, courts should order the provision of treatments already incorporated in the SUS and, when there is evidence that a patient needs a treatment that is available for private purchase and no effective alternative is offered, then non-incorporated drugs can be provided via judicial order. Thus, the effort to provide courts with more knowledge, information and technical support from doctors and pharmacists would allow them to decide if the alternative treatment offered by the SUS is effective or if the patient really needs the treatment available in the private market but not provided by the SUS.

However, it is questionable whether better trained judges assisted by doctors and pharmacists will be able to acquire and evaluate factual information to make sound policy decisions. Even if we reduce these decisions to a mere medical/scientific issue, it would be unrealistic to expect that a group of doctors and pharmacists will have the necessary diversification of expertise to be able to make a comprehensive scientific assessment of all the treatments that are being litigated for. This task is even more daunting considering that the main driver of litigation is a wide array of new medical technologies for various health problems. In countries where health technology assessment is taken seriously, this task is carried out by highly specialised and resourced agencies and scientific committees that are able to gather and assess large amounts of data applying stringent scientific methods and with a constant dialogue between stakeholders and experts.

\footnotetext{
${ }^{87}$ See Guido Calabresi and Philip Bobbit, Tragic Choices (1978).
} 
Nonetheless, let's assume, for the sake of the argument, that courts supported by health professionals can create a system that is able to assess treatments using sound evidence. That will still not solve all the problems caused by right to health litigation because the provision of healthcare in a health system is not merely a medical problem that science can solve. It is a matter of public policy. Doctors and pharmacists will not be able to consider costeffectiveness, affordability, opportunity costs, public health priorities and the preferences of other stakeholders before deciding on the provision of treatment.

Even if we add specialists from other fields to the group of medical experts, it would still be naïve to expect that their decision would give a ready-made answer to whether or not a treatment should be provided. Priority setting involves problems of social fact (e.g. how a certain disease affects the population's health), polycentricity (e.g. the socio-economic effects of providing a given treatment on the public health system), politics (e.g. the priorities of a community with regards to healthcare spending) and morality (how to distribute healthcare fairly given that we cannot give everything to everyone) that cannot be reduced to a technical decision that can be objectively made by a body of experts attached to courts.

Public policy decisions are inescapably speculative and the impact of which is hard to predict. ${ }^{88}$ It is the role of managerial capacity to make and review decisions according to the consequences and to respond promptly to changing circumstances. This highlights the importance of the decisions' procedural legitimacy. Since there is no unequivocal right decision, it is essential that it be made according to a fair procedure. ${ }^{89}$

From this perspective, the expectation that courts make good administrative and political decisions with better trained judges and expert assistance, but without the virtues of the public administration (e.g. expertise and flexibility) and of a politically accountable

\footnotetext{
${ }^{88}$ King, supra n 78 at ch. 9.

${ }^{89}$ See Norman Daniels, Just Health: meeting health need fairly (2009).
} 
process, seems untenable. ${ }^{90}$ Moreover, those advantages of the political and administrative decisions may be undermined by decisions of reviewing courts which reverse choices from the political and administrative sphere based on a different source of evidence. ${ }^{91}$

To overcome some of these obstacles, one could imagine the CNJ recommending the creation of a very sophisticated 'bureaucracy under judicial auspices' to carry out health technology assessments and decide on whether a treatment should be provided in each case. ${ }^{92}$ Even if we assume that courts have the resources and capacity to do so, it can be questioned whether this would be more sensible than relying on, and controlling, the procedure used on the administrative level by health authorities who have the structure and expertise to perform this task. The section that follows will discuss this argument further.

\section{B. The Federal Law 12.401/11: Health Technology Assessment}

Federal Law 12.401/2011 was based on two draft bills: the 338/2007, proposed by Senator Flávio Arns (hereafter Arns' Bill); and the 219/2007, by Senator Tião Vianna (hereafter Vianna's Bill). Both draft bills state that the right to health litigation is the main justification for their enactment. Nevertheless, they see the problem from different perspectives and put forward different solutions for it.

In the official justification for his draft bill, Senator Arns affirms that the access to healthcare cannot be restricted by clinical protocols and guidelines or by official lists of treatments. According to him, the official lists of treatments are not frequently updated, restricting patients' access to new technologies. He also mentioned that the assessment and incorporation of health technologies is not made through a formal administrative process,

\footnotetext{
${ }^{90}$ On the importance of expertise and flexibility to decide on welfare policy issues see King, supra $\mathrm{n} 78$ at $\mathrm{ch} .8$ and 9.

${ }^{91}$ See Kenneth Davis, Discretionary justice: a preliminary inquiry (1971) at 118; Adrian Vermeule, Law and the Limits of Reason (2009) at 50.

${ }^{92}$ The idea of a 'bureaucracy under judicial auspices' to assist courts in cases involving legislative facts was suggested by Davis, ibid., and has been recently advanced by Paul Yowell, 'Empirical Research in Rights-Based Judicial Review of Legislation' in PM Huber and K Ziegler (eds), Current Problems in the Protection of Human Rights-Perspectives from Germany and the UK (2012).
} 
which means that there is no deadline for the assessments to be concluded, no right to administrative appeal, and no participation from civil society. He proposed the creation of an institution - composed of government representatives and civil society - for assessing health technologies and deciding on their incorporation in the SUS through a formal administrative procedure. However, the government would still have to provide treatments not incorporated in the SUS if the already incorporated treatments are not effective and there is a medical prescription declaring that the treatment is necessary to avoid death or serious harm to the patient.

Vianna's Bill had a different entry point. In his draft's justification, Senator Vianna affirmed that the provision of drugs ordered by courts is forcing the public purchase of high cost treatments the effectiveness of which is not always proven. According to him, this is harmful for the SUS because it gives pharmaceutical companies the power to lobby patients and doctors to convince them that the treatments they sell are the best and that patients can access them free of cost through courts. He affirms that because resources are scarce, priorities have to be set by the SUS in order to benefit the largest number of people. Vianna's Bill also proposed that the SUS should only provide treatments that are registered with the ANVISA and included in the official lists of treatments. Thus, Vianna's Bill would give health authorities the final decision on the provision of healthcare and would make nonjusticiable claims for drugs not incorporated in the SUS.

In spite of the different proposals and opposing perspectives, both draft bills were analysed conjointly by the National Congress because, according to the Senate, they legislate about the same issue. Vianna's Bill was formally rejected and Arns' Bill was approved to become Federal Law 12.401/2011. However, the proposals put forward by Vianna's Bill were introduced as amendments to Arns' Bill. Thus, Federal Law 12.401/2011 is actually an amalgam of both draft bills: it incorporated the rule that the SUS should only provide 
treatments that are incorporated in the SUS (as proposed by Vianna's Bill) and also created an institution responsible for assessing health technologies through a formal administrative procedure (as proposed by Arns’ Bill).

Federal Law 12.401/11 then established that the provision of treatment in the SUS can only be made according to the lists, the clinical protocols and guidelines issued by the SUS. It also banned the provision of, or reimbursement for, experimental treatments and drugs not registered with the ANVISA or not authorized by it. These rules are, in principle, similar to those established by the STF after the public hearing and by the CNJ's recommendation. The main difference is the regime proposed for treatments not incorporated in the SUS or claimed for off-protocol use, which are the main drivers of litigation. The CNJ and the STF give courts the power to decide in these cases. Federal Law 12.401/11 does not allow this exception.

Federal Law 12.401/11 created a new institution - the National Council for Incorporation of Technologies in the National Health System (CONITEC) - responsible for carrying out health technology assessments in order to inform decisions on the incorporation and exclusion of health technologies by the SUS, as well as the creation or alteration of clinical protocols and guidelines. CONITEC assesses health technologies based on the scientific evidence regarding their effectiveness, accuracy and safety, as well as health economic evaluation by comparing how a new technology compares with those already incorporated in terms of cost-effectiveness.

This legislation also established that the incorporation, exclusion or alteration of treatments has to be made through an administrative procedure that is open to public participation by means of public audiences and public consultancy. The appraisal will be made by independent experts in universities and the assessment has to be concluded within 180 days starting from the beginning of the administrative process, and extended by a further 
90 days, if necessary. Interested parties also have the right to administrative appeal against the decisions.

Presidential Decree 7646/2011, which regulates Federal Law 12.401/11, established that CONITEC is composed of representatives from many health related public institutions, civil society and the Ministry of Health. This Decree also added that the CONITEC's reports will be forwarded to the Ministry of Health Secretary for Science and Technology (SCTIE) for the final decision on the incorporation of a technology. If the SCTIE decides to incorporate the assessed technology, then the treatment has to be made available in the SUS within 180 days.

Before the final version of Federal Law 12.401/11 was approved, the President of the Republic vetoed the article which stated that, if the deadline for the conclusion of a technology's assessment was reached and no decision had been issued, then the technology should have to be available in the SUS until the decision is finally made. She also vetoed an article stating that the economic impact of a technology is not a reason to deny its incorporation in the SUS. The justifications given for both vetoes are very similar. The President asserted the importance of scientific and economic assessment of a health technology before any decision on its provision is made. She affirmed that providing nonassessed treatments can bring risk to patients' health and is an inadequate way of allocating public resources. Moreover, according to her, the SUS has to consider the economic impact of a treatment in order to optimize and rationalize the allocation of public funds.

Differently from the responses by the STF and the $\mathrm{CNJ}$, which give courts the last word on the provision of non-incorporated drugs, Federal Law 12.401/2011 makes it clear that the decision on the provision of healthcare should be in the hands of health authorities. It created a specialised institution and an administrative process to decide on the incorporation of new 
technologies that is expected to be more inclusive, transparent, accountable, fast and scientifically robust.

According to CONITEC's first body of directors, the pressure for the incorporation of new health technologies comes from many groups in society - including patients and pharmaceutical industries - but they are especially concerned about judicial decisions that compel the provision of drugs based on 'the right to health as an individual rather than a collective right'. ${ }^{93}$ According to them, there is a common opinion among judges and the general public that if a drug is not provided, it is because the SUS is badly managed. Within this context, they argue that it is necessary to review the public policies for health technology assessment by increasing the number of clinical protocols and guidelines, updating them more frequently and making the procedure for incorporation of new technologies more transparent and participative. ${ }^{94}$

After the enactment of Federal Law 12.401/11, the Federal Attorney General's Office (AGU), the institution responsible for the legal representation of the federal government, issued several Legal Opinions (Pareceres ${ }^{95}$ ) determining a new strategy for government lawyers to respond to right to health litigation claims. The Legal Opinions affirm that, in response to the increase in the number of lawsuits claiming treatments against the SUS, which are mostly based on weak scientific evidence, it is important for the government's lawyers to make reference to the institution and the administrative procedure created by Federal Law 12.401/11. The strategy is to convince courts that the SUS's pharmaceutical policy is based on methodologically stringent scientific investigation that aims at

\footnotetext{
${ }^{93}$ Helaine Capucho et al., 'Incorporation of Techonologies in Health in Brazil: a New Model for the Brazilian Public Health System (Sistema Único de Saúde - SUS)' (2011), 13 Boletim do Instistuto de Saúde 215.

94 Ibid.

${ }^{95}$ AGU's legal opinions bind all the federal government lawyers.
} 
guaranteeing that the treatments provided are safe, effective and, at the same time, rationalize and optimize the allocation of financial resources. ${ }^{96}$

Thus, the history of Federal Law 12.401/2011, the analysis of its first body of directors, and the Legal Opinions issued by the AGU have all made clear the government's strategy to use CONITEC and the new administrative procedure to convince courts not to review healthcare rationing decisions. The government is working on the assumption that a better administrative procedure for health technologies assessment - more transparent, participative, accountable, timely and scientifically sophisticated - is conducive to promoting a more deferential attitude from courts and, consequently, control right to health litigation and reduce its impact on the public health system.

This does not mean that courts have no role in controlling the decisions made by health authorities. AGU's Legal Opinion 804/2012, for instance, suggests that instead of reviewing rationing decisions based on its own sources of evidence and policy analysis, courts can order the assessment of the claimed drug and control the legality and reasonableness of the procedure carried out by CONITEC. This idea will be explored further in the Conclusion of this article.

\section{CONCLUSION}

Right to health litigation in Brazil rules out from the start the possibility of choosing the treatments that will do the most good from a population perspective. It makes the public health system less efficient because an enormous amount of resources is spent based on poor evidence and in a way that does not maximize the benefits that it can provide. It also creates unfairness because it generates a two-tier public health system and distributes resources according to patients' capacity to litigate.

\footnotetext{
${ }^{96}$ See Legal Opinions 803/2012; 804/2012; 805/2012; 810/2012.
} 
It would certainly be possible to cherry pick some decisions in which the application of the right to health as an individual trump delivered a right decision, i.e. granting healthcare for a patient who was denied a treatment that was actually safe, effective, cost-effective, affordable and needed. However, this is not a good argument to justify courts applying the right to health like most of them do in Brazil. If courts order the provision of almost any treatment that patients claim, then both right and wrong decisions will be delivered without criteria to distinguish between them. What is needed is a procedure that allows a more efficient and fair allocation of resources.

This connects to my argument that the responses from the STF and the CNJ are incomplete. Their underlying assumption is that courts can deal appropriately with allocative decisions in healthcare if they go beyond the limits imposed by the traditional adjudicative model and try to incorporate attributes that are normally present in the administrative and legislative arena. As Donald Horowitz observed, '[I]nstitutions in competition with each other tend to resemble each other. Each assumes the characteristics of the other in order to minimize competitive disadvantages' ${ }^{97}$ This is perceived as a way to make sure that health authorities do a good job and, if they do not, to substitute judicial rulings for their decisions.

However, the question is whether, and under what circumstances, they can do a better job than the primary decision-maker. ${ }^{98}$ Why should courts try to build their own institutional capacity and legitimacy to make substantial decisions on the provision of healthcare when there is an institution created and equipped in the administrative level specifically to make them? If the administrative procedure is good (transparent, accountable and based on robust evidence and fair principles), then why replicate it under the auspices of courts? It would be naïve to expect that courts create a procedure to decide on the provision of healthcare that is

\footnotetext{
${ }^{97}$ Horowitz, supra $\mathrm{n} 70$ at 141 .

${ }^{98}$ Ibid. at 207
} 
better than the one that can be made at the administrative level. This would also be unnecessarily costly.

If health authorities' procedure is defective, then it would be better if courts controlled the procedure, occasionally ordering a decision to be remade, rather than ignoring more or less entirely what was decided by health authorities and trying to decide it from scratch. Instead of engaging with scientific issues (e.g. whether treatment A is better than B) or moral, economic and policy reasons (e.g. to balance the needs of a claimant against those of others and the budgetary capacity of the state), which courts are ill-suited to do if compared with health authorities, courts could do a better job in overseeing and scrutinizing the procedure through which these decisions were made and guaranteeing the adequate conditions for a fair and rational decision.

This is how the Judiciary in England, Canada, Australia and New Zealand have been judging claims for the provision of healthcare. ${ }^{99}$ Courts in these countries tend to control health authorities' decisions-making process, giving special attention to procedural fairness, transparency and factors that may have been overlooked by the primary decision-maker. If a flaw in the process is found, instead of ordering the provision of a treatment or the reallocation of healthcare resources, courts tend to, by way of remedy, quash the decision and remit the issue back to the government authority for reconsideration in light of the judgment.

A similar approach in claims for health treatments is expected from Brazilian courts with the enactment of Federal Law 12.401/11. Judicial control of procedure is facilitated by a more inclusive, transparent, accountable and scientifically informed health technology assessment system. Moreover, it can be expected that such a procedure will be seen by courts

\footnotetext{
${ }^{99}$ See Colleen Flood and Insyia Essajee. 'Setting limits on health care: challenges in and out of the courtroom in Canada and down-under' in Andre den Exeter and Martin Buijsen (eds) Rationing Health Care: Hard Choices and Unavoidable Trade-offs (2012); Flood and Gross, supra n 2; Syrett, supra n 2; Newdick, supra $n 2$ at 107; Christopher Newdick, 'Accountability for rationing - theory into practice' (2005) 33(4) Journal of Law, Medicine and Ethics 660.
} 
as being more legitimate and hence attract greater judicial deference. ${ }^{100}$ And considering that courts should take into account the quality of the public authorities' inquiry into the specific case, it also makes sense for them to exercise deference for epistemic reasons. ${ }^{101}$

This would not make the right to health non-justiciable, but would imply a significant change in the way it is interpreted by courts. Instead of judging the right to health as an individual trump against rationing decisions made by the public health system, it would be applied as the right to access a healthcare system in which resources are distributed according to a fair process, which includes duties of transparency, accountability, consistency and use of adequate evidence. ${ }^{102}$ Future research will be able to assess the impact of Federal Law $12.401 / 11$ in order to test whether the most adequate response to right to health litigation was actually effective. If so, then it will be interesting to note the paradox that litigation, by creating unfairness and inefficiency, may have forced the SUS to be fairer and more efficient.

\section{ACKNOWLEDGEMENTS}

Earlier versions of this paper were presented at the UCL Conference on Latin American Law \& Policy, at the XXXI International Congress of the Latin American Studies Association and at the Getúlio Vargas Foundation Law School Research Seminar. I am grateful to those who contributed to this article on those occasions. I am also especially indebted to Conor Gearty, Thomas Poole and Octavio Ferraz for comments on previous versions of this article. The usual disclaimer applies.

\footnotetext{
100 The hypothesis that courts are more deferential to rationing decisions when health authorities' reasons and procedures are explicit was suggested by Daniels, supra n 89 at 123 and Flood and Essajee, supra n 99 at 184.

${ }^{101}$ On the idea of deference for epistemic reasons see Aileen Kavanagh, 'Defending Deference in Public Law and Constitutional Theory' (2010), 126 Law Quarterly Review 222; T Allan, 'Judicial Deference and Judicial Review: Legal Doctrine and Legal Theory’ (2011), 127 Law Quarterly Review 117.

${ }^{102}$ A similar idea of the right to health was proposed by Daniels, supra $\mathrm{n} 89$ at 328-330.
} 